\title{
CRESCIMENTO INICIAL E ÍNDICES DE CLOROFILA DE MANJERICÃO cv. MARIA BONITA CULTIVADO SOB DIFERENTES CONDIČÕES DE LUMINOSIDADE E CONCENTRAÇÕES DE POTÁSSIO
}

Lavine Silva Matos ${ }^{1}$; Diego dos Santos Souza ${ }^{2}$; Nalbert Silva dos Santos²; Gilvanda Leão dos Anjos ${ }^{2}$; Anacleto Ranulfo dos Santos ${ }^{3}$.

1. Mestre em Solos e Qualidade de Ecossistemas da Universidade Federal do Recôncavo da Bahia/UFRB (lavinematos@yahoo.com.br). Cruz das Almas - Brasil.

2. Graduando (a) em Engenharia Agronômica da UFRB.

3. Professor Doutor da UFRB.

Recebido em: 08/04/2016 - Aprovado em: 30/05/2016 - Publicado em: 20/06/2016

DOI: 10.18677/Enciclopedia_Biosfera_2016_034

\begin{abstract}
RESUMO
Avaliaram-se a influência de diferentes condições de luminosidade e das concentrações de potássio no crescimento de manjericão cv. "Maria Bonita". O trabalho foi executado no período de junho a julho de 2015, no campo experimental da UFRB, em Cruz das AImas/BA. O delineamento do experimento foi em parcela subdividida, em esquema fatorial $5 \times 3$, sendo cinco concentrações de potássio $(\mathrm{K})$ : $0,30,60,120,180 \mathrm{~kg} \mathrm{ha}^{-1}$ de $\mathrm{K}_{2} \mathrm{O}$ e três condições de luminosidade: malha Fotoconversora ChromatiNet $B$ Vermelha, malha Termorefletora Aluminet $\AA$ e ambiente de pleno sol, com sete repetições, num total de 105 unidades experimentais (vasos), permanecendo uma planta/vaso. Houve efeito significativo da interação entre as condições de luminosidade e as doses de potássio $(p \leq 0,05)$ pelo teste $\mathrm{F}$ da ANAVA para a variável número de folhas, enquanto que as demais variáveis apresentaram efeito isolado do ambiente.
\end{abstract}

PALAVRAS-CHAVE: Malhas coloridas, Ocimum basilicum L., potássio.

\section{INITIAL GROWTH AND CLOROFILA INDICES OF BASIL GROWN IN DIFFERENT ENVIRONMENTS AND POTASSIUM CONCENTRATIONS}

\begin{abstract}
In order to evaluate the influence of different cultivation environments and potassium (K) contents on the growth of basil plants (cv. "Maria Bonita"), a study was conducted from June to July 2015, at the experimental field of the Federal University of Recôncavo of Bahia - UFRB, in Cruz das Almas/BA, Brazil. The experiment was set in a split-plot design, using a $5 \times 3$ factorial scheme, which corresponded to five $\mathrm{K}$ contents $\left(0,30,60,120\right.$ and $180 \mathrm{~kg} \mathrm{ha}^{-1}$ of $\left.\mathrm{K}_{2} \mathrm{O}\right)$ and three light environments (ChromatiNet $\AA$ photoconverterred-colored net, Aluminet@thermo-reflectivenetand and full sun), with seven replicates, totaling 105 experimental units (pots), with one plant/pot. Significant effect of the interaction between light environments and $K$ contents $(p \leq 0.05)$ by $F$ test of the analysis of
\end{abstract}


variance was observed for the parameter number of leaves, while the others were not influenced by the interaction, but for the environment.

KEYWORDS: colored nets, Ocimum basilicum L., potassium.

\section{INTRODUÇÃO}

O manjericão (Ocimum basilicum L.), que pertence a família Lamiaceae, faz parte de um grupo de plantas aromáticas e medicinais de grande valor econômico, muito utilizado para diversos fins: ornamental, condimentar, medicinal, aromático, na indústria de perfumaria e de cosméticos. É uma espécie herbácea, bastante aromática, e pode ser anual ou perene conforme o local de plantio (CARVALHO FILHO et al., 2006). A cultivar Maria Bonita possui, em média, 45,50 cm de altura e hábito de crescimento ereto, o que, de forma geral, favorece a sua colheita, seja manual ou mecanizada (BLANK et al., 2007).

A luz é essencial para as plantas e além de fornecer energia utilizada no processo fotossintético, pode gerar sinais que porventura regularão 0 seu desenvolvimento. Portanto, alterações nos espectros luminosos aos quais uma determinada espécie está adaptada, podem proporcionar variadas respostas fisiológicas, anatômicas e/ou de crescimento (ATROCH et al., 2001). Tanto as respostas morfológicas das plantas quanto as fisiológicas, não dependem somente da presença, redução ou ausência de luz, mas inclusive, do espectro da radiação (TAIZ \& ZEIGER, 2006).

A malha fotoconversora aumenta a eficiência fotossintética das culturas, pois modificam o espectro da luz solar, e por isso torna-se capaz de refletir e redirecionála, aumentando, assim, sua captação pelas plantas em decorrência do efeito da difusão de luz, que é em média de $15 \%$ a $20 \%$. A malha fotoconversora vermelha caracteriza-se por reduzir as ondas azuis, amarelas e verdes, e por acrescentar ondas na região do vermelho distante e vermelho, com transmitância acima de $590 \mathrm{~nm}$ (POLYSACK, 2015), enquanto que, a malha termo-refletora AlumiNet permite manejar a oscilação de temperatura que ocorre entre o período diurno e noturno, o que possibilita a formação de microclimas diversos, a depender da malha utilizada e, além disso, protegem as plantas da radiação excessiva do sol, além de conservar o calor no interior do ambiente (COSTA et al., 2012).

Segundo MARSCHNER (1995) a nutrição mineral contribui para a composição da organização estrutural da planta, ou seja, quando esta recebe ou deixa de receber macro e micronutrientes, fica evidente as modificações na sua estrutura anatômica que porventura podem alterar a espessura dos tecidos e os conteúdos de pigmentos. Ainda segundo o autor, o potássio $(K)$ possui importantes funções, como ativação de enzimas, abertura e fechamento dos estômatos, regulação da turgidez do tecido, no controle da concentração de $\mathrm{CO}_{2}$ na câmara subestomática, na realização da fotossíntese, síntese de proteínas e translocação de carboidratos, além de reduzir os danos causados por secas, geadas ou salinidade.

Dessa forma, o estudo da influência dos ambientes de luminosidade e da adubação potássica no crescimento e no desenvolvimento do manjericão visa oferecer aos produtores desta cultura, alternativas mais efetivas para obter resultados significativamente mais econômicos na produção agronômica dessas plantas. Portanto, espera-se que a interação entre ambientes de luminosidade e concentrações de potássio, proporcione às plantas de manjericão, respostas 
significativas quanto as variáveis avaliadas. Assim, o objetivo desse estudo foi avaliar a influência dos ambientes de luminosidade e das concentrações de potássio no crescimento inicial e nos índices de clorofila de manjericão cv. Maria Bonita.

\section{MATERIAL E MÉTODOS}

O trabalho foi executado entre junho a julho de 2015, em casa de vegetação, no campo experimental da Universidade Federal do Recôncavo da Bahia (UFRB), no município de Cruz das Almas/BA, que está localizado geograficamente a 12\%0'19"S e 3906'22'W, a uma altitude de $225 \mathrm{~m}$.

O solo foi classificado como GLEISSOLO (EMBRAPA, 2013), e possui as características químicas na camada de $20 \mathrm{a} 40 \mathrm{~cm}$, a seguir: $\mathrm{pH}\left(\mathrm{em} \mathrm{H}_{2} \mathrm{O}\right)=5,0$; $\mathrm{Al}$ trocável $\left(\mathrm{Cmolc} \mathrm{dm}^{-3}\right)=1,95 ; \mathrm{Ca}+\mathrm{Mg}\left(\mathrm{Cmolc} \mathrm{dm}{ }^{-3}\right)=1,0 ;$ P-Mehlich $1\left(\mathrm{mg} \mathrm{dm}^{-3}\right)=2,0$; $\mathrm{K}\left(\mathrm{Cmolc} \mathrm{dm}{ }^{-3}\right)=0,05$; Matéria Orgânica $\left(\mathrm{g} \mathrm{Kg}^{-1}\right)=10,0$; Saturação por bases $(\mathrm{V} \%)=$

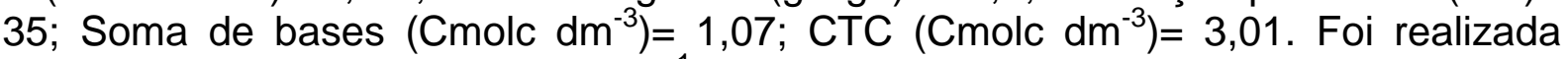
calagem com $600 \mathrm{~kg} \mathrm{CaCO}_{3} \mathrm{ha}^{-1}$, e posteriormente, fosfatagem com $300 \mathrm{~kg}$ de Superfosfato Simples ha ${ }^{-1}$.

Foram utilizadas sementes de manjericão cv. Maria Bonita - um dos genótipos de Ocimum basilicum L. - provenientes da Fazenda Experimental Campus Rural da Universidade Federal de Sergipe - UFS. As mudas foram produzidas em casa de vegetação na UFRB, em sementeira de 120 células, contendo substrato comercial. Aos 21 dias após a semeadura, as plântulas foram transferidas para vasos plásticos com capacidade para $5 \mathrm{~kg}$ de substrato, contendo solo e composto orgânico comercial (4:1).

$O$ experimento foi delineado de forma inteiramente casualizada (DIC) em esquema de parcela subdividida, com fatorial $5 \times 3$, sendo cinco concentrações de potássio $(\mathrm{K}): 0,30,60,120,180 \mathrm{~kg} \mathrm{ha}^{-1} \mathrm{de} \mathrm{K}_{2} 0$, tendo como fonte o cloreto de potássio $(\mathrm{KCl})$ e 3 ambientes de luminosidade: $A$. malha Fotoconversora ChromatiNet ${ }^{\circledR}$ Vermelha, B. malha Termo-refletora Aluminet $\circledast$, e C. pleno sol (cultivo fora das malhas). Assim, o experimento 105 unidades experimentais (vasos), permanecendo uma planta/vaso. $\mathrm{Na}$ semana seguinte ao transplantio as plantas receberam os tratamentos, e durante todo o período do estudo foram irrigadas diariamente visando manter o substrato com umidade suficiente para suprir as necessidades das plantas.

As plantas foram avaliadas aos 30 dias após a aplicação dos tratamentos, e posteriormente avaliaram-se: altura da planta (AP), medida com fita milimétrica, tomando-se do colo até o ápice da planta; número de folhas (NF), por meio de contagem direta; diâmetro de caule (DC), com o auxílio de paquímetro digital (precisão de $0,01 \mathrm{~mm}$ ); e pigmentos fotossintéticos, utilizando a média de três folhas do terço médio de cada planta (Clorofilômetro Eletrônico - clorofiLOG CFL 1030 da Falker), de 08 as 10 horas da manhã.

A ANOVA dos dados foi realizada por meio do programa SISVAR (FERREIRA, 2011), e em função do nível de significância será aplicado o teste de Tukey $(p<0,05)$ e de regressão para identificar o efeito do ambiente e das doses de potássio, respectivamente.

\section{RESULTADOS E DISCUSSÃO}

Verificou-se efeito significativo da interação entre as doses de potássio e os ambientes de luminosidade $(p<0,05)$ pelo teste $F$ da ANOVA para a 
variável número de folhas, enquanto que as demais variáveis não apresentaram efeito da interação (Tabela 1).

TABELA 1. Resumo da ANOVA para as variáveis de crescimento de manjericão cv. "Maria Bonita" (Ocimum basilicum L.) cultivadas em diferentes condições de luminosidade e concentrações de potássio.

\begin{tabular}{|c|c|c|c|c|c|c|c|}
\hline \multirow{2}{*}{$\begin{array}{c}\text { Fontes de } \\
\text { Variação }\end{array}$} & \multirow{2}{*}{ GL } & \multirow{2}{*}{ AP } & \multirow{2}{*}{ DC } & \multirow{2}{*}{ NF } & \multicolumn{3}{|c|}{ - CLOROFILA - } \\
\hline & & & & & $a$ & $b$ & Total $(a+b)$ \\
\hline & & & - & QUADRAD & OS MÉL & OS & \\
\hline$A L$ & 2 & $763,33^{*}$ & $12,11^{*}$ & $2448,46^{*}$ & $14,37^{*}$ & $7,27^{\mathrm{ns}}$ & $38,64^{*}$ \\
\hline Resíduo a & 6 & 10,51 & 0,51 & 204,11 & 1,86 & 5,56 & 8,69 \\
\hline $\mathrm{D}$ & 4 & $12,41^{\mathrm{ns}}$ & $0,23^{\mathrm{ns}}$ & $1294,36^{*}$ & $0,97^{\mathrm{ns}}$ & $7,58^{\mathrm{ns}}$ & $11,31^{\mathrm{ns}}$ \\
\hline$A L X D$ & 8 & $8,32^{\mathrm{ns}}$ & $0,94^{\mathrm{ns}}$ & $995,46^{*}$ & $1,94^{\mathrm{ns}}$ & $4,75^{\mathrm{ns}}$ & $6,66^{\mathrm{ns}}$ \\
\hline Resíduo b & 24 & 5,46 & 0,47 & 364,83 & 1,75 & 5,56 & 8,06 \\
\hline CV 1 (\%) & & 8,46 & 9,40 & 9,35 & 6,06 & 36,88 & 10,19 \\
\hline CV 2 (\%) & & 6,09 & 9,03 & 12,51 & 5,87 & 36,89 & 9,81 \\
\hline Media geral & & 38,34 & 7,64 & 152,73 & 22,54 & 6,39 & 28,94 \\
\hline
\end{tabular}

$\mathrm{AL}$ - ambiente de luz; D - dose de potássio; AP - altura da planta $(\mathrm{cm})$; DC - diâmetro do caule $(\mathrm{cm})$; NF - número de folhas; CLO A - clorofila $a$; CLO B - clorofila $b$; CLO T clorofila total; ${ }^{\text {ns }}$ - não significativo; * - significativo ao nível de $5 \%$ pelo teste $\mathrm{F}$.

O efeito isolado do ambiente de luz apresentados na Tabela 2 foi significativo para as variáveis diâmetro do caule, altura da planta, clorofila $a$, b e total $(a+b)$.

TABELA 2. Médias da Altura da Planta (AP), diâmetro do caule (DC), número de folhas (NF), clorofila $a, b$ e total (CL $a, C L b$ e Total) de plantas de manjericão cv. "Maria Bonita" (Ocimum basilicum L.) cultivadas em diferentes condições de luminosidade.

\begin{tabular}{cccccc}
\hline $\begin{array}{c}\text { Ambientes de } \\
\text { Luz }\end{array}$ & $\begin{array}{c}\text { AP } \\
(\mathbf{c m})\end{array}$ & $\begin{array}{c}\text { DC } \\
(\mathbf{m m})\end{array}$ & CL $\boldsymbol{a}$ & $\mathbf{C L} \boldsymbol{b}$ & CL Total $(\boldsymbol{a}+\boldsymbol{b})$ \\
\hline Malha Vermelha & $42,14 \mathrm{a}$ & $7,61 \mathrm{~b}$ & $21,81 \mathrm{~b}$ & $6,00 \mathrm{a}$ & $27,81 \mathrm{~b}$ \\
Malha Aluminizada & $39,76 \mathrm{~b}$ & $7,06 \mathrm{c}$ & $22,82 \mathrm{a}$ & $6,28 \mathrm{a}$ & $29,10 \mathrm{ab}$ \\
Pleno Sol & $33,13 \mathrm{c}$ & $8,24 \mathrm{a}$ & $23,00 \mathrm{a}$ & $6,89 \mathrm{a}$ & $29,89 \mathrm{a}$
\end{tabular}

Médias seguidas pelas mesmas letras minúsculas nas colunas não diferem estatisticamente entre si pelo teste de Tukey $(p<0,05)$.

Sobre os efeitos da interação entre o ambiente de luz e as doses de potássio, observa-se na Figura 1, a variável número de folhas (NF), cujas plantas sob a malha vermelha apresentaram melhor ajuste ao modelo polinomial quadrático, em que a derivação da equação possibilitou estimar a dose de $99,5 \mathrm{~kg} \mathrm{ha}^{-1}$ de $\mathrm{K}$, que proporcionou o maior valor desta variável, que foi em média, de 177 folhas.

Ao comparar-se a dose zero de $\mathrm{k}$, cujo número médio foi de 155 folhas e a dose de $180 \mathrm{~kg} \mathrm{ha}^{-1}$ de $\mathrm{K}$, que apresentou em média 163 folhas à dose estimada, nota-se acréscimo de $12,5 \%$ e redução de $8,2 \%$ no NF, respectivamente. As plantas sob a malha aluminizada e a pleno sol (controle: plantas cultivadas fora das malhas) não diferiram estatisticamente entre si, e apresentaram melhores ajustes ao modelo polinomial linear, tendo na dose máxima de potássio aplicada, 
as plantas de manjericão cultivas sob a malha aluminizada e a pleno sol, em média, 143 e 155 folhas, respectivamente.

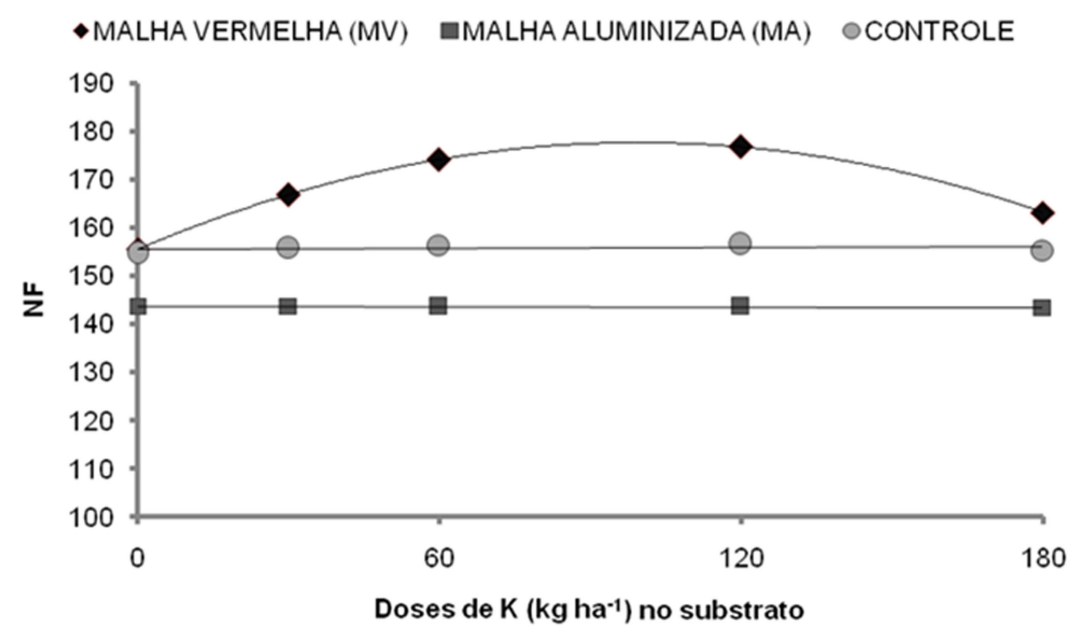

FIGURA 1. Número de folhas (NF) de manjericão (Ocimum basilicum L.) cultivadas em diferentes condições de luminosidade e concentrações de potássio. $M V_{-} \hat{y}=155,509950-0,446434 x+0,00224 x^{2}$ $R^{2}=0,3748 ; M A-\hat{y}=143,727011-0,001628 x$ $\mathrm{R}^{2}=0,3602 ; \quad$ Controle (Pleno Sol)_ $\hat{\mathrm{y}}=$ $139,847701+0,095115 \times R^{2}=0,4269$.

Diante dos dados apresentados é possível inferir que o manjericão sob a malha vermelha, cuja dose estimada foi $99,5 \mathrm{~kg} \mathrm{ha}^{-1}$ de $\mathrm{K}$, produziram mais folhas do que os cultivados nos outros ambientes de luminosidade (malha aluminizada e pleno sol), mesmo estas recebendo a dose máxima de K. Isto é, para as plantas sob malha vermelha percebe-se uma otimização na produção de folhas pelas plantas, que mesmo na dose estimada, emitiriam mais folhas do que nos outros ambientes de luminosidade, mesmo quando aplicada a dose máxima de potássio. Ademais, mesmo comparando os três ambientes de luz, na dose máxima aplicada, o manjericão cultivado sob a malha vermelha, ainda assim, emitiram mais folhas do que as plantas crescidas nos demais ambientes de luminosidade, devido ao estímulo propiciado pela malha vermelha associada à adubação potássica.

JESUS et al. (2013) em estudo com mudas de girassol submetidas a doses de potássio (em solução nutritiva), verificaram que houve elevação do número de folhas das mudas até a dose estimada de $173,86 \mathrm{mg} \mathrm{L}^{-1} \mathrm{~K}$. No que diz respeito à qualidade do espectro de luz, SOUZA et al., (2013) constataram que plantas Mentha piperita L. sob malha vermelha apresentaram folhas em maior número quando comparada as plantas a pleno sol, que diferiram significativamente.

$\mathrm{Na}$ Figura 2 está representada a altura das plantas (AP) de manjericão crescidas sob a malha vermelha, diferiu estatisticamente das plantas sob a malha aluminizada e a pleno sol (controle). Percentualmente, a AP crescidas sob malha fotoconversora vermelha foi $5,6 \%$ e $21,2 \%$ superiores as plantas sob a malha aluminizada e sob sol pleno, respectivamente. Já as crescidas sob a malha aluminizada apresentaram altura $16,5 \%$ superior às plantas sob pleno sol. Segundo TAIZ \& ZEIGER (2004), o sombreamento induz as plantas a alocarem 
maior parte de seus recursos para o crescimento em altura, e tal desempenho é conhecido como "resposta de evitação da sombra".

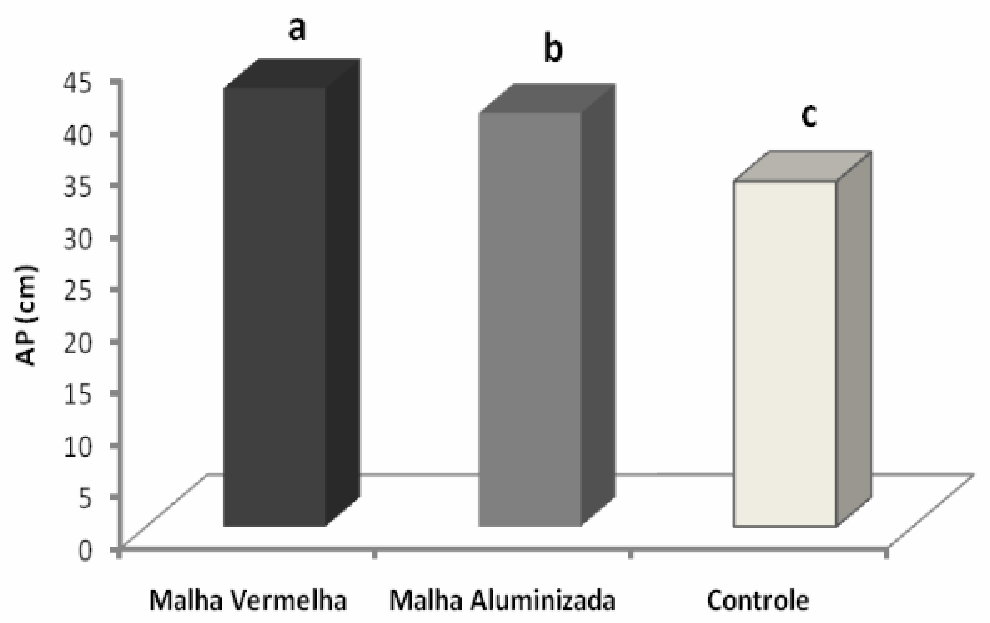

FIGURA 2. Altura das plantas (AP) de manjericão cV. Maria Bonita (Ocimum basilicum L.) em diferentes condições de luminosidade.

Este resultado corrobora os de FERREIRA et al. (2014), que ao investigarem o efeito das telas coloridas em rúcula, concluíram que o telado vermelho exerceu influencia positiva quanto a altura das plantas e, aquelas crescidas a sol pleno foram as que apresentaram menor altura média em relação as plantas sob telas coloridas. HIRATA \& HIRATA (2015), ao avaliarem agrião d'água cultivado em solo sob malhas de sombreamento, também encontraram resultados similares aos deste estudo, de forma que as plantas do ambiente de sol pleno também apresentaram altura inferior.

Por outro lado, SOUZA et al. (2014) estudando alecrim crescido sob malhas fotoconversoras concluíram que as plantas do ambiente de pleno sol foram maiores, não havendo diferença estatística entre as crescidas sob malhas. Nesse caso, os autores atribuíram essa resposta ao efeito da intensidade luminosa, pois o alecrim é mais adaptado a climas mais ensolarados e secos.

As plantas do ambiente de pleno sol (controle: fora das malhas) diferiram estatisticamente e apresentaram diâmetro do caule (DC) maior do que das plantas sob as malhas vermelha e aluminizada (Figura 3). A diminuição da intensidade da luz, independentemente da alteração de seu espectro, condicionou as plantas a terem caules de menor diâmetro. Em termos percentuais, o DC das plantas a pleno sol foi $7,6 \%$ e $14,3 \%$ superior as plantas sob a malha fotoconversora vermelha e sob ambiente de pleno sol, respectivamente. As plantas sob a malha vermelha apresentaram $\mathrm{DC} 7,2 \%$ superior às plantas do ambiente de pleno sol.

Resultados semelhantes aos deste estudo foram encontrados por MARTINS et al. (2008), ao avaliarem o crescimento de O. gratissimum L., constataram que as plantas do ambiente de pleno sol exibiram diâmetro da haste maior que as plantas sob malhas, revelando que a diminuição da intensidade luminosa, mesmo que não altere seu espectro, condiciona caule mais estreito. De forma semelhante, SOUZA et al. (2014), ao estudarem o alecrim, constataram que as plantas do ambiente de pleno sol possuíram maior DC que as sob malha vermelha. 


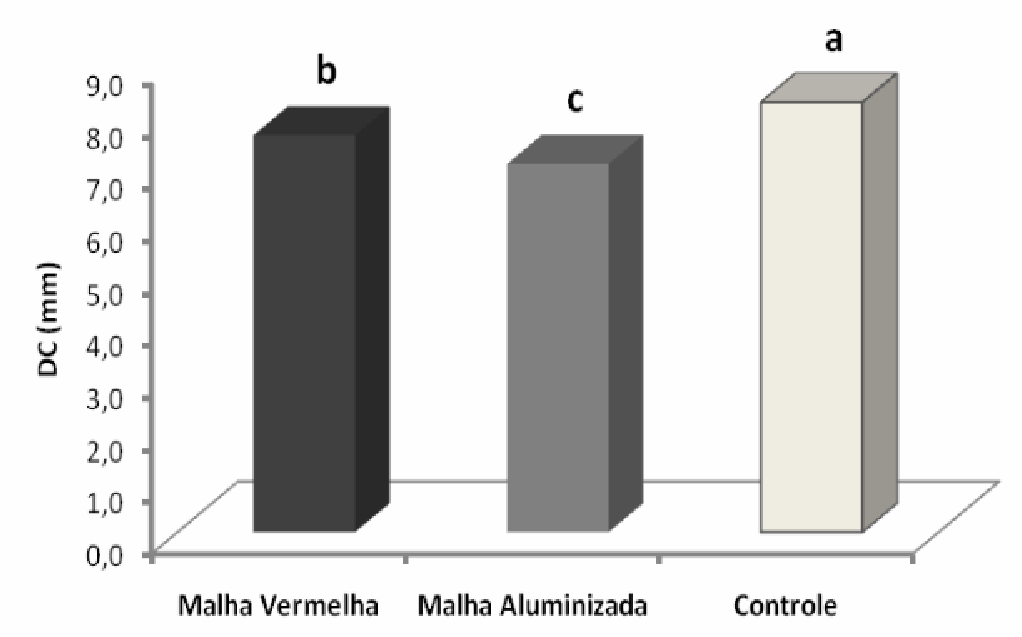

FIGURA 3. Diâmetro do caule de manjericão cv. Maria Bonita (Ocimum basilicum L.) em diferentes condições de luminosidade.

Em contrapartida, ABREU et al. (2013), ao pesquisarem os efeitos das malhas coloridas no crescimento de manjericão, constataram ausência de diferença significativa para esta variável. Da mesma forma, OLIVEIRA et al., (2009) não observaram variação no diâmetro da haste de Artemisia vulgaris $L$ cultivadas a sol pleno das crescidas sob malhas de proteção coloridas.

A Figura 4 apresenta os índices de clorofila $a, b$ e total $(a+b)$ por ambiente de luz. Para clorofila $a$, não houve diferença estatística significativa entre o manjericão cultivado em ambiente a pleno sol (controle: fora das malhas) e sob a malha aluminizada, e sim entre estes e os cultivados sob a malha fotoconversora vermelha. A diferença percentual encontrada foi de $5,1 \%$ e $4,4 \%$ entre as plantas do cultivo de pleno sol e a malha aluminizada, respectivamente, em relação sob malha fotoconversora vermelha.

Em relação à clorofila $b$, não apresentou diferença estatística entre os 3 ambientes de luminosidade. A clorofila total não apresentou diferença estatística entre as plantas do ambiente de sol pleno e as sob a malha aluminizada, porém houve entre o ambiente de pleno sol e a malha vermelha, que foi de $6,9 \%$. A intensidade luminosa influenciou sobremaneira os teores dos índices fotossintéticos das plantas de mil folhas, no experimento de PINTO et al. (2014), tendo a análise mostrado que, à exceção da clorofila $a$, houve diferenças estatísticas significativas para os índices de clorofilas $b$ e clorofila total entre os tratamentos empregados, em que valores mais elevados destas variáveis foram observados na malha aluminizada, que é empregada para o controle térmico devido ao bloqueio da radiação infravermelha, mas não altera os espectros de onda nas faixas do azul e do vermelho (POLYSACK, 2015).

De forma contrária, ao estudarem características fisiológicas de Melissa officinalis L. sob diferentes condições de luz, BRANT et al. (2010) notaram que as plantas sob cultivo a sol pleno tiveram valores de clorofila total menor que os demais tratamentos, indicando, assim, que o sombreamento favoreceu a produção deste pigmento para a espécie. Na espécie Eugenia uniflora também ocorreu alteração no teor de clorofila $a$, clorofila b e clorofila total em plantas sob diferentes intensidades de luz (MIELKE et al., 2010). 


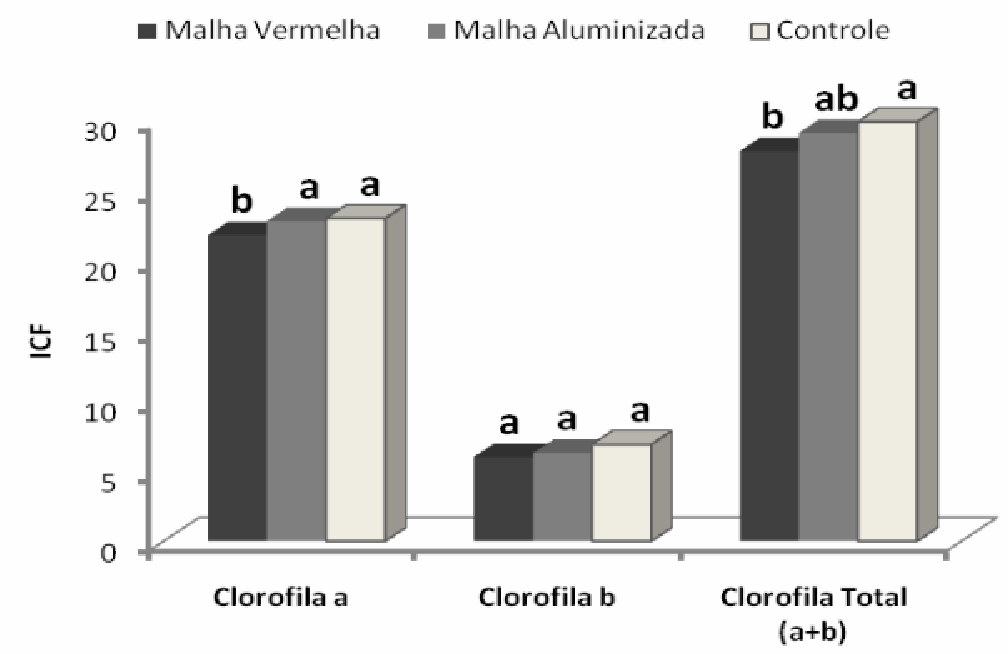

FIGURA 4. Clorofila $a, b$ e total $(a+b)(I C F)$ de manjericão cv. Maria Bonita (Ocimum basilicum L.) em diferentes condições de luminosidade.

KRAMER \& KOZLOWSKI (1979) explicam que níveis de clorofilas nas folhas são controlados pela luz, porém, em intensidades de luz mais elevadas, as moléculas de clorofilas são mais propensas a processos de foto-oxidação, em que o equilíbrio é estabelecido em níveis de radiação mais baixas. Dessa forma, folhas de sombra possuem, em linhas gerais, maior concentração de clorofilas em relação às cultivadas sob sol pleno (ALVARENGA et al., 2003).

As respostas apresentadas pelas plantas à variação na disponibilidade de luz costumam envolver, ainda alterações nas folhas relacionadas aos índices de clorofila. Ainda assim, a resposta pode variar de forma considerável entre espécies em decorrência da capacidade de aclimatarem-se e a dependência da qualidade e quantidade da luz (TAIZ \& ZEIGER, 2009).

\section{CONCLUSÕES}

O número de folhas foi influenciado pela interação ambiente de luz e doses de potássio. A malha vermelha proporcionou maior altura do manjericão. No ambiente de pleno sol o manjericão apresentou maior valor de diâmetro de caule, assim como os índices de clorofila a e clorofila total.

\section{AGRADECIMENTOS}

Os autores agradecem a Universidade Federal do Recôncavo da Bahia (UFRB) e a Fundação de Amparo à Pesquisa do Estado da Bahia (FAPESB).

\section{REFERÊNCIAS}

ABREU, C. B.; SANTOS, A. R.; SOUZA, G. S.; OLIVEIRA, U. C.; SILVA, J. S. Qualidade de luz no crescimento inicial de plantas de manjericão (Ocimum basilicum L.) em ambiente controlado. Enciclopédia Biosfera, v. 9, p. 1855, 2013.

ALVARENGA, A. A.; CASTRO, E. M.; LIMA JUNIOR, É. C.; MAGALHÃES, M. M. Effects of differents ligth levels on the initial growth and photosynthesis of Croton ENCICLOPÉDIA BIOSFERA, Centro Científico Conhecer - Goiânia, v.13 n.23; p. 395 
urucurana Baill. In southeastern Brazil. Revista Árvore, Viçosa, v. 27, n. 1, p. 53-57, 2003. Disponível em: <http://dx.doi.org/10.1590/S0100-67622003000100007>. Doi: $10.1590 /$ S0100-67622003000100007.

ATROCH, E. M. A. C.; SOARES, A. M.; ALVARENGA, A. A.; CASTRO, E. M.; Crescimento, teor de clorofilas, distribuição de biomassa e características anatômicas de plantas de Bauhinia forficata submetidas a diferentes condições de sombreamento. Revista Ciência e Agrotecnologia, v. 25, p. 853-862, 2001. Disponível em: <http://dx.doi.org/10.1590/S0103-84782005000500016>. Doi: 10.1590/S0103-84782005000500016.

BLANK, A. F.; SOUZA, E. M.; ARRIGONI-BLANK, M. F.; PAULA, J. W. A.; ALVES, P. B. Maria Bonita: cultivar de manjericão tipo linalol. Pesquisa Agropecuária Brasileira, v. 42, n. 12, p. 1811-1813, 2007. Disponível em: <http://dx.doi.org/10.1590/S0100-204X2007001200020 >. Doi: 10.1590/S0100204X2007001200020

BRANT, R. S.; PINTO, J. E. B. P.; ROSAL, L. F.; CASTRO, E. M.; OLIVEIRA, C.; ALBUQUERQUE, C. J. B. Características fisiológicas e anatômicas de Melissa officinalis L. (Lamiaceae) cultivadas sob diferentes condições de luz. Magistra, v. 22, p. 146-152, 2010.

CARVALHO FILHO, J. L. S.; BLANK, A.F.; ALVES, P. B.; EHLERT, P. A.D.; MELO, A. S.; CAVALCANTI, S.C.H.; ARRIGONI-BLANK, M. F.; SILVA-MAN, R.Influence of the harvesting time, temperature and drying period on basil (Ocimum basilicum L.) essential oil. Revista Brasileira de Farmacognosia, v. 16, p. 24-30, 2006. Disponível em: <http://dx.doi.org/10.1590/S0102-695X2006000100007>. Doi: 10.1590/S0102-695X2006000100007.

COSTA, A. G.; CHAGAS, J. H.; PINTO, J. E. B. P.; BERTOLUCCI, S. K. V. Crescimento vegetativo e produção de óleo essencial de hortelã-pimenta cultivada sob malhas. Pesquisa Agropecuária Brasileira, v. 47, n. 4, p. 534-540, 2012.

EMBRAPA. Sistema Brasileiro de Classificação de Solos. 3 ed. Ver. Ampl. - Brasilia, DF: Embrapa, 2013. 353 p.

FERREIRA, M. M. A. A. S.; SOUZA, G. S.; SANTOS, A. R. Produção de mudas de rúcula em diferentes substratos cultivadas sob malhas coloridas. Enciclopédia Biosfera, v. 10, n. 18; p. 2429-2440, 2014.

FERREIRA, D. F. Sisvar: A computer statistical analysis system. Ciência e Agrotecnologia, v. 35, n. 6, p. 1039-1042, 2011.

HIRATA, A. C. S.; HIRATA, E. K. Desempenho produtivo do agrião d'água cultivado em solo sob telas de sombreamento. Pesquisa Agropecuária Brasileira, v. 50 , n. 10, p. 895-901, 2015. Disponível em: <http://dx.doi.org/10.1590/S0100204X2015001000005>. Doi: 10.1590/S0100-204X2015001000005. 
JESUS, F. N.; ALVES, A. C.; SANTOS, A. R.; SOUZA, G. S.; CERQUEIRA, T. T. Mudas de girassol submetidas a doses de potássio. Enciclopédia Biosfera, v. 9, n. 16 ; p. 1554-1565, 2013.

KRAMER, P. J; KOZLOWSKI, T. T. Physiology of wood plants, New York Academic Press, 1979. 811p.

MARTINS, J. R.; ALVARENGA, A. A.; CASTRO, E. M.; PINTO, J. E. B. P.; SILVA, A. P. O. Avaliação do crescimento e do teor de óleo essencial em plantas de Ocimum gratissimum L. cultivadas sob malhas coloridas. Revista Brasileira de Plantas Medicinais, v. 10, n. 4, p. 102-107, 2008.

MARSCHNER, H. Mineral nutrition of higher plants. San Diego: Academic Press. 889 p. 1995.

MIELKE, M. S.; SCHAFFER, B. Photosynthetic and growth responses of Eugeniauniflora L. seedlings to soil flooding and light intensity. Environmental and Experimental Botany, v. 68, p. 113-121, 2010.

OLIVEIRA, M. I.; CASTRO, E. M.; COSTA, L. C. B.; OLIVEIRA, C. Características biométricas, anatômicas e fisiológicas de Artemisia vulgaris $\mathrm{L}$. cultivada sob telas coloridas. Revista Brasileira de Plantas Medicinais, v. 11, n. 1, p. 56-62, 2009. Disponível em: <http://dx.doi.org/10.1590/S1516-05722009000100010>. Doi: 10.1590/S1516-05722009000100010.

PINTO, J. E. B. P.; FERRAZ, E. O.; BERTOLUCCI, S. K. V.; SILVEIRA, H. R. O.; SANTOS, A. R.; SILVA, G. M. Produção de biomassa e óleo essencial em mil folhas cultivada sob telas coloridas. Horticultura Brasileira, v. 32, n. 3, p. 321-326, 2014. Disponível em: <http://dx.doi.org/10.1590/S0102-05362014000300014>. Doi: 10.1590/S0102-05362014000300014.

POLYSACK INDÚSTRIAS Ltda. Malhas fotoconversoras. Disponível em: <http://ginegarpolysack.com.br/>. Acesso em 12 de maio de 2015.

SOUZA, G. S.; SILVA, J. S.; OLIVEIRA, U. C.; SANTOS NETO, R. B.; SANTOS, A. $R$. Crescimento vegetativo e produção de óleo essencial de plantas de alecrim cultivadas sob telas coloridas. Bioscience Journal, v. 30, n. 3, 2014.

SOUZA, G. S.; OLIVEIRA, U. C.; SILVA, J. S.; LIMA, J. C. Crescimento, produção de biomassa e aspectos fisiológicos de plantas de Mentha piperita L. cultivadas sob diferentes doses de fósforo e malhas coloridas. Global ScienceTechnology, v. 06, n. 03, p.35-44, 2013.

TAIZ, L.; ZEIGER, E. Fisiologia vegetal. 4.ed. Porto Alegre: Artmed, 2009. 819p. 